\title{
$\mathrm{PH} 102$ actualiad
}

\section{El European Research Centre cumple diez años desde su fundación}

El European Research Centre for Book and Paper Conservation-Restoration (ERC) es una iniciativa interdisciplinar internacional surgida en 2010 que está adscrita a la Universidad de Krems (Austria) y representada en 35 países. Aspira a convertirse en un centro de referencia en la investigación de la conservación-restauración de los libros y el papel. A lo largo de este decenio ha participado en numerosos proyectos de investigación, cursos de formación y publicaciones.

María Dolores Díaz de Miranda Macías | representante para España del ERC

URL de la contribución <http://www.iaph.es/revistaph/index.php/revistaph/article/view/4817>

El European Research Centre for Book and Paper Conservation-Restoration (ERC) es fruto de una iniciativa interdisciplinar que surgió de la comunidad de conservadores-restauradores, archiveros, bibliotecarios y otros profesionales de toda Europa como respuesta a la necesidad de buscar métodos de preservación, conservación y restauración más adecuados para tratar el patrimonio documental gráfico. Sus objetivos siguen dos grandes líneas de actuación: por un lado, iniciar, apoyar y ejecutar la investigación en el campo de la conservación-restauración de los libros y los documentos; y, por otro, comunicar y difundir los resultados de la investigación para que puedan ser aplicarlos en patrimonio documental.

En mayo de 2011 tuvo lugar, en Horm (Austria), la primera conferencia organizada por el ERC, a la que asistieron más de 150 participantes y ponentes de 50 países europeos, EE.UU., Japón, India y Australia. Este encuentro dio al centro su base profesional e itinerario de trabajo. Se comprobó que las tres grandes causas que destruyen el $80 \%$ del patrimonio documental europeo son la desintegración del papel formado con pastas madereras, el ataque de los hongos y las bacterias y los efectos corrosivos de las tintas metaloácidas.

Se consideraron como importantes actividades subordinadas a este centro la protección y la primera respuesta ante desastres. También se vio la necesidad de investigar en el desarrollo de la teoría de la conservación y el sistema de valores de conservación; y en otros temas

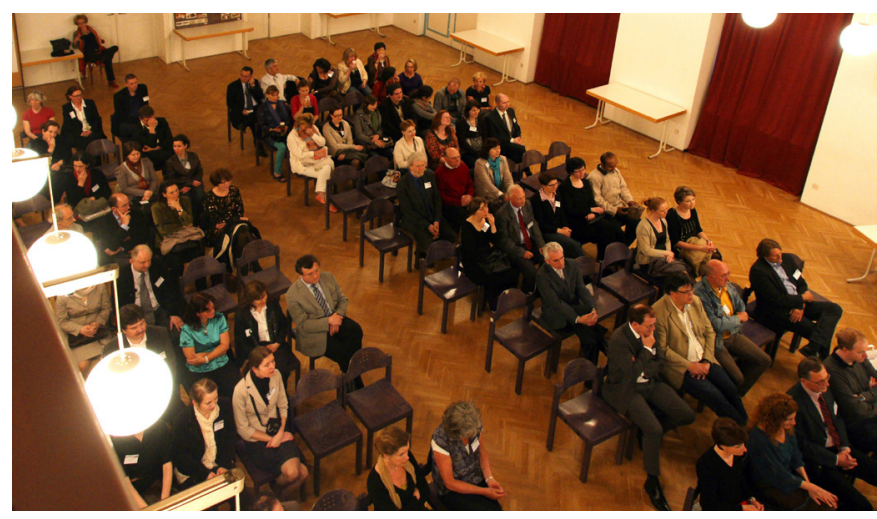

Primera conferencia organizada por el ERC, Horm (Austria) 2011 | foto ERC, fuente de todas las imágenes

menores como la degradación de los materiales proteicos o los aspectos intangibles del patrimonio material.

En 2014, el ERC dio un paso decisivo para el desarrollo y la difusión de sus proyectos de investigación: se afilió a la University of Continuing Education de Krems situándose bajo el paraguas del Zentrum für Kulturgüterschutz adscrito a la Donau-Universität de Krems (Austria).

Las actividades del 2020 tuvieron que repensarse y ajustarse a la nueva realidad derivada del COVI-19. Los encuentros en línea han facilitado la continuidad y estimulado la creación de espacios plurales para el intercambio de información. Se conmemoraron los diez años del centro con la conferencia Book conservation-One Philosophy-Many Interpretations, celebrada 


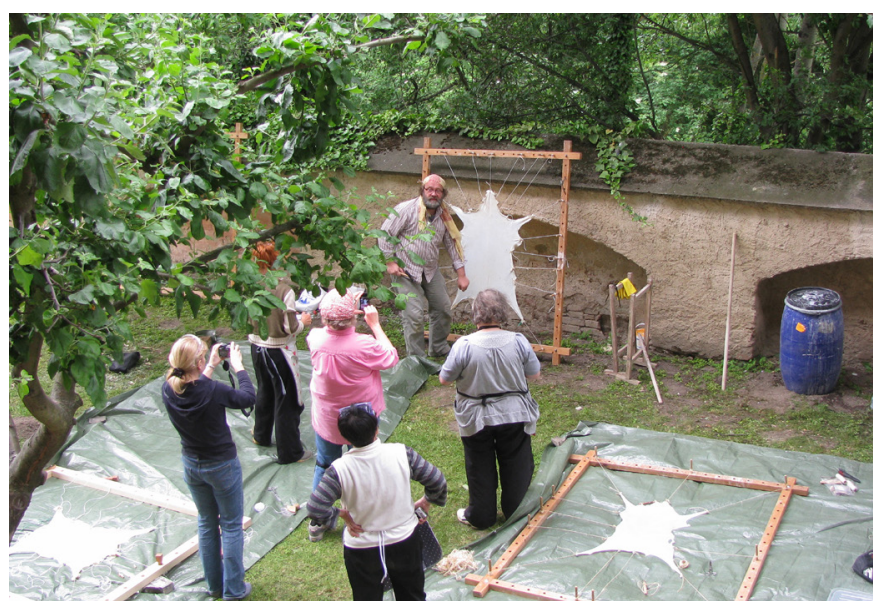

Curso de fabricación de pergamino. Profesor Jiri Vnoucek conservador de manuscritos en la Biblioteca Real de Dinamarca, Copenhague. Horn 2012

el 4 y 5 de noviembre. El tema de la misma se centró en la teoría y la filosofía de la conservación como base de todas las decisiones y actuaciones conservadoras. Presentaron sus trabajos profesionales de renombre, conservadores emergentes, profesores universitarios y líderes de la conservación procedentes de todo el mundo (Austria, Polonia, Eslovenia, Irlanda, Nueva Zelanda, Italia, Croacia, Turquía, España, Grecia, Bulgaria, Estados Unidos, Italia, Yemen, Portugal, México, Egipto, Kosovo, Ucrania, Macedonia del Norte, Rusia, Lituania y Armenia). Los asistentes inscritos superaron los 600 .

Organizativamente, el centro cuenta con una Junta que formula el enfoque científico, proporciona los servicios para su gestión y asegura su viabilidad económica. La constituyen nueve miembros de diversas instituciones y países. Al frente de ella está Patricia Engel. Además, hay un equipo de 35 representantes nacionales que son el puente de comunicación con sus respectivos países.

También cuenta con numerosos socios de cooperación: otras universidades, centros de investigación y socios industriales. Además de voluntarios y sponsors.

El ERC ha formado parte de proyectos de investigación como Deacimic FFG (para el deterioro del papel de pulpa de madera), Men and Books, Stop Fungi, Affandi I, Affandi III (sobre el ataque de moho), Sinai III, Beasts

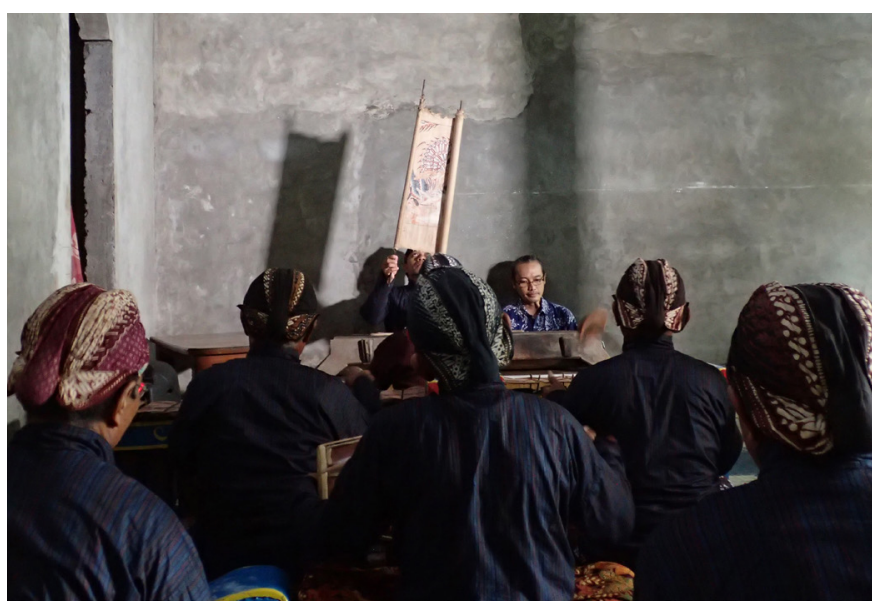

Proyectos del ERC en Indonesia, Yogyakarta 2019

to Craft (B2C) (que se ocuparon de la degradación del material de colágeno o las técnicas de encuadernación de libros históricos), o Affandi IV y Affandi V (sobre el concepto de higiene sostenible).

La difusión de sus investigaciones la hace a través del curso universitario Interdisciplinary Methods of Graphic Arts, Books and Document Conservation, impartido por la Universidad de Educación Continua de Krems; de los cursos intensivos iniciados en la ciudad de Horn (20112013), que se han vuelto a retomar en 2019, con la escuela de verano LIGATUS y el curso dedicado a las tintas, organizado en paralelo a la Ink Corrosion Conference IIC- (Krems, octubre 2019); del intercambio de estudiantes ERASMUS, y conferencias, publicaciones y artículos promovidos por el propio ERC o por otras instituciones que se lo solicite. El ERC también es responsable de la publicación periódica digital Conservation Update, que se descarga de forma gratuita desde su web.

Otros recursos que ofrece la web del ERC es la lista actualizada de relevantes conferencias, simposios, etc. en torno a la conservación-restauración, además del innovador motor de búsqueda MuLiBiNe, que permite al ingresar una palabra clave en cualquier idioma obtener las referencias a todos los artículos de dicho tema. Asimismo cuenta con una Biblioteca; los libros se pueden solicitar en préstamo. La consulta de los títulos se hace a través de la web del ERC. 